\title{
Physiologic Insulin Resensitization as a Treatment Modality for Insulin Resistance Pathophysiology
}

\author{
Frank Greenway ${ }^{1}$, Brian Loveridge ${ }^{2}$, Richard M. Grimes ${ }^{3}$, Tori R. Tucker ${ }^{4}$, Michael Alexander ${ }^{5}$, \\ Scott A. Hepford ${ }^{6}$, Justin Fontenot ${ }^{7}$, Candi Nobles-James ${ }^{8}$, Carol Wilson ${ }^{9}$, Adam M. Starr ${ }^{10}$, \\ Mohammed Abdelsaid ${ }^{11}$, Stanley T. Lewis ${ }^{12}$ and Jonathan R. T. Lakey ${ }^{5, *}$
}

check for updates

Citation: Greenway, F.; Loveridge, B.; Grimes, R.M.; Tucker, T.R.; Alexander, M.; Hepford, S.A.; Fontenot, J.; Nobles-James, C.; Wilson, C.; Starr, A.M.; et al. Physiologic Insulin Resensitization as a Treatment Modality for Insulin Resistance Pathophysiology. Int. J. Mol. Sci. 2022, 23, 1884. https://doi.org/ $10.3390 /$ ijms 23031884

Academic Editors

Francesco Chiarelli, Paolo Moghetti and Maria Elisabeth Street

Received: 22 December 2021

Accepted: 3 February 2022

Published: 8 February 2022

Publisher's Note: MDPI stays neutral with regard to jurisdictional claims in published maps and institutional affiliations.

Copyright: (C) 2022 by the authors. Licensee MDPI, Basel, Switzerland. This article is an open access article distributed under the terms and conditions of the Creative Commons Attribution (CC BY) license (https:// creativecommons.org/licenses/by/ $4.0 /)$.
1 Clinical Trials Unit, Pennington Biomedical Research Center, Louisiana State University, Baton Rouge, LA 70808, USA; frank.greenway@pbrc.edu

2 Diabetes Relief, Layton, UT 84041, USA; brian@diabetesrelief.com

3 Department of Internal Medicine, McGovern Medical School, University of Texas Health Science Center, Houston, TX 77030, USA; richard.m.grimes@uth.tmc.edu

4 Department of Development and Cell Biology, University of California Irvine, Irvine, CA 92617, USA; trtucker@uci.edu

5 Department of Surgery, University of California Irvine, Orange, CA 92868, USA; michaela@hs.uci.edu

6 Well Cell Global LLC, Houston, TX 77079, USA; scott@wellcellglobal.com

7 Lafayette Arthritis and Endocrine Clinic, Lafayette, LA 70506, USA; justinfontenotmd@gmail.com

8 Division of Endocrinology, Mercer University School of Medicine, Macon, GA 31207, USA; nobles-james_cn@mercer.edu

9 Well Cell Support LLC, Houston, TX 77079, USA; carol@wellcellsupport.com

10 Department of Orthopedic Surgery, Asheville Orthopedic Associates P.A, Asheville, NC 28801, USA; adam@kalamountain.com

11 Biomedical Sciences Department, Mercer University School of Medicine, Savannah, GA 31404, USA; abdelsaid_ma@mercer.edu

12 Eselle Health, Inc., La Jolla, CA 92037, USA; slewis@esellehealth.com

* Correspondence: jrtlakey@gmail.com; Tel.: +1-714-851-8856

\begin{abstract}
Prevalence of type 2 diabetes increased from 2.5\% of the US population in 1990 to $10.5 \%$ in 2018. This creates a major public health problem, due to increases in long-term complications of diabetes, including neuropathy, retinopathy, nephropathy, skin ulcers, amputations, and atherosclerotic cardiovascular disease. In this review, we evaluated the scientific basis that supports the use of physiologic insulin resensitization. Insulin resistance is the primary cause of type 2 diabetes. Insulin resistance leads to increasing insulin secretion, leading to beta-cell exhaustion or burnout. This triggers a cascade leading to islet cell destruction and the long-term complications of type 2 diabetes. Concurrent with insulin resistance, the regular bursts of insulin from the pancreas become irregular. This has been treated by the precise administration of insulin more physiologically. There is consistent evidence that this treatment modality can reverse the diabetes-associated complications of neuropathy, diabetic ulcers, nephropathy, and retinopathy, and that it lowers HbA1c. In conclusion, physiologic insulin resensitization has a persuasive scientific basis, significant treatment potential,
\end{abstract} and likely cost benefits.

Keywords: insulin resistance; diabetes; metabolic disorder; obesity; insulin infusion; physiologic insulin resensitization; PIR; treatment modality; neuropathy; nephropathy; retinopathy; cardiovascular disease; chronic kidney disease; CKD

\section{Introduction}

The prevalence of type 2 diabetes has increased from $2.5 \%$ of the US population in 1990 and constituted $10.5 \%$ of the total US population or $13.0 \%$ of US adults in 2018 [1]. This is an astounding 320\% increase in 28 years. In addition, a third of American adults, approximately 88 million people, have prediabetes [2]. Patients with pre-diabetes will 
progress to diabetes at a rate of $5-10 \%$ per year [3]. While, currently, we have a major diabetes-associated health care problem, a surge of new diabetes patients looms. An already overburdened health care system can expect major increases in the long-term complications of type 2 diabetes, which include neuropathy, retinopathy, nephropathy, ulcers, amputations, and atherosclerotic cardiovascular disease. Diabetes is a very expensive disease that cost the US economy in 2017 an estimated \$327 Billion in direct medical costs and another $\$ 90$ Billion in lost productivity. Given that the annual direct medical cost for treating diabetes increased from \$245 Billion to \$327 Billion per year between 2012 and 2017 [4], it is not unreasonable to assume that the cost of treating diabetes in 2021 will approach $\$ 400$ Billion. This expenditure is high and increasing because it is directed toward a progressive disease for which therapy is designed to slow the progression of diabetes-associated conditions until death occurs.

We first turned our attention to the most current guidelines from the American Diabetes Association (ADA), which has recommend the use of medications classified as sodium-glucose cotransporter 2 inhibitors (SGLT2is) and glucagon-like peptide 1 receptor agonists (GLP-1 RAs) for individuals with T2D on Metformin AND diagnosed with EITHER heart failure (HF) OR chronic kidney disease (CKD) [5], as clearly discussed by Colling, et al. [6]. They conclude that "the introduction of SGLT2is and GLP-1RAs has led to rapid changes in recommendations for the medical management of T2D" [6]. Moreover, Colling, et al. detail classes of patients for whom preferential use of GLP-1RAs and SGLT2is is and is notrecommended, and we urge a thorough review by practitioners [6]. The ADA's "Standards of Medical Care in Diabetes" was originally approved in 1988 and the work is updated annually, most recently in December of 2020. Considerations and requirements are discussed in "Introduction: Standards of Medical Care in Diabetes-2021" [7].

We also note that the Food \& Drug Administration (FDA) has published a March 2020 Update to its Drug Safety Communications from 2015 [8]. Further, The American College of Cardiology published on January 19, 2021, an expert analysis by Rishav Adhikari and Michael Blaha, who found that (1) uptake of these cardioprotective drugs in 2020 remained low; (2) cardiologists account for a minute percentage of prescribing for these drugs, even though their primary benefit is cardiovascular risk reduction; and (3) barriers to adoption by cardiologists include lack of knowledge about these medications and cardiologists perception that diabetes care is not their responsibility [9].

Clearly, costs will rise, side effects and FDA warnings will always be prevalent, and disability will continue to occur. However, there is a complimentary treatment that reverses the major underlying pathophysiologic mechanism that leads to T2DM with far fewer negatives, if any. This treatment is effective because it directly reverses insulin resistance (IR), not just the individual manifestations of diabetes. Moreover, unlike other medications cited, side effects are minimal, if at all. For nearly forty years, researchers and clinicians have utilized a treatment modality that dynamically administers periodic infusions of insulin that bio-mimic the non-diabetic's natural secretions and rest periods of insulin from the pancreas [4]. There have been multiple articles describing this treatment approach that have reported efficacious clinical outcomes on various diabetic comorbidities. Although effective, the exact cellular and molecular mechanisms behind the use of periodic infusions of insulin was undetermined. This article has two purposes: (1) To explore insulin resistance pathophysiology and (2) to review literature for clinical outcomes and molecular mechanisms that support the use of physiologic insulin resensitization as an effective treatment modality to address insulin resistance, of which diabetes and its complications are the most common results.

\section{The Rise of Type 2 Diabetes}

In general, two main hypotheses were generated for the etiology and pathogenesis of type-2 DM. The first hypothesis is that the development of insulin resistance (IR) is behind type 2 diabetes. IR causes hyperglycemia, which is the cause of most diabetic complications. IR also causes hyperinsulinemia, i.e., the over-production of insulin by $\beta$ beta cells. Over 
time, beta cells will be exhausted and die, which leads to further disease progression and more hyperglycemia. The second hypothesis concerns the defect in insulin secretion, which is well reported in type 2 diabetes.

As stated, type 2 diabetes is driven by IR. A common perception of type 2 diabetes progression is that the IR is countered by increasing insulin secretion until the beta cells in the pancreas can no longer keep up with the insulin demand and die progressively of exhaustion [3]. Another possible sequence of events is that the IR could begin with a defect in insulin secretion. A defect in the first phase of insulin secretion is well known to be an early characteristic of type 2 diabetes $[10,11]$

Therefore, an alternative explanation for the progression of type 2 diabetes is that impaired insulin secretion is a corollary to the progression of obesity, thus, triggering a cascade leading to islet cell destruction and the long-term complications of type 2 diabetes. In this manuscript, we offer the hypothesis that it is an insulin secretion defect that drives the IR responsible for the pathophysiology of type 2 diabetes.

\section{Physiologic Hormone Secretion}

Hormones that are released in an oscillatory pattern have receptors that are physiologically designed to bind the ligand, bring it into the cell, separate the receptor from its ligand and return the receptor to the cell surface. This rest period, or trough, of these oscillations gives sufficient time for this physiologic sequence to take place prior to the next peak in this cycle. When hormone receptors designed to respond to pulses of its ligand are exposed to constant stimulation with the hormone, the receptors down-regulate and become "tolerant" or "resistant" to stimulation. The amount of down regulation can be variable; for example, the gonadotropin-releasing hormone receptor is an example of a receptor that is particularly sensitive to down-regulation from a constant stimulation by its ligand. Leuprolide is a long-acting agonist of the gonadotropin-releasing hormone receptor that is given as an injection and stimulates the receptor continuously for 1-3 months. This receptor agonist down-regulates the receptor to the extent that the sex hormone secretion is blocked. In fact, leuprolide is used to block puberty or to achieve a chemical castration in the treatment of hormone-sensitive cancer [12].

\subsection{Physiologic Insulin Secretion}

Physiologic insulin consists of discrete oscillatory secretions and distinct rest periods to stimulate ligand/receptor activation. The beta cell secretes insulin with a dynamic periodicity of 4-8 $\mathrm{min}$, and most commonly 5-6 min, based on the body's demands (Figure 1) [13].

Beta cells in the islets are in close contact to one another, which allows islets to secrete insulin in such a pattern, but it requires a network of autonomic nerves to allow the pancreatic beta cells to coordinate this dynamic profile [14]. The insulin pulses are responsible for timing of dynamic glucagon secretion that occur normally anti-synchronous from the cycling of insulin [15]. Measuring the cycling of insulin is made more difficult by the fact that the beta cells secrete the insulin into the portal circulation and the concentrations in the portal vein are five times higher than in the peripheral circulation due to hepatic extraction [16]. The insulin receptor in its upregulated state senses a basal level of insulin that is about $30 \%$ of the total, and $70 \%$ is due to pulses secreted over that baseline. The increase in insulin at meals is accounted for by an increase in the amplitude of the insulin spikes and not a change in the time between oscillations. Although there is a high rate of clearance of insulin by the liver, $\mathrm{C}$-peptide is secreted in an equimolar ratio to insulin, but C-peptide reaches the peripheral circulation without hepatic clearance. The deconvolution method of measuring the spike frequency from the peripheral blood depends on the differential kinetics of insulin and C-peptide [16]. Insulin resistance (IR) is associated with a reduction in the amplitude of insulin cycling and an increase in the basal level of insulin, creating more of a constant rather than oscillatory pattern of insulin stimulation of its receptor. Although obesity is associated with an increase in beta cell mass, by the time type 2 diabetes develops, there has been a $65 \%$ reduction in beta cell mass due to apoptosis associated with increased 
levels of amylin that is secreted in equimolar amounts to insulin [17]. This reduced beta cell mass loses the ability to maintain insulin oscillation, and a reduction in glucose-stimulated insulin secretion leads to hyperglycemia. The peripheral level of insulin is higher with an increased ratio of proinsulin to insulin, but the peaks in insulin secretion are not as high as in people with normal glucose tolerance. The lack of insulin pulses decreases hepatic clearance of insulin leading to peripheral hyperinsulinemia [18]. The insulin receptor can bind insulin in two ways, with high affinity and with low affinity. The affinity decreases as the insulin levels increase. Thus, the changing of receptor affinity for insulin is another property that contributes to hyperinsulinemia [19].
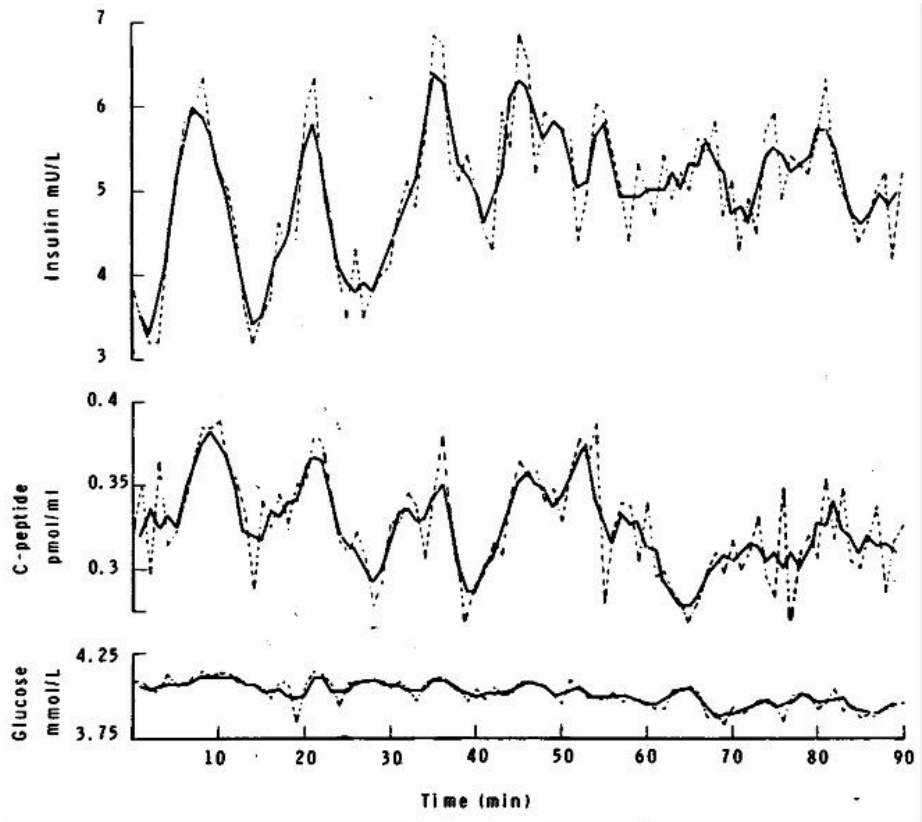

Figure 1. A three-minute moving average (continuous line) of the fasting plasma insulin, C-peptide and glucose concentrations taken at one-minute intervals. The dashed line shows the "unsmoothed" data. Smoothing reduces the rapid fluctuations, which are probably due to "noise," and also blunts the amplitude. The simultaneous insulin and C-peptide cycles disappear after $50 \mathrm{~min}$. Reproduced from [13].

\subsection{Insulin Sensitivity and Physiologic Secretion}

The importance of oscillatory secretion signals in insulin sensitivity has been demonstrated in several ways. In patients with type 2 diabetes, an overnight infusion of somatostatin gave the beta cell a rest from constant stimulation by insulin and restored insulin pulse mass and normal insulin secretion [20]. Hepatic IR in dogs was achieved with a constant infusion of insulin that produced a 50\% increase in the portal vein level of insulin [21]. Even more convincing was a study in which physiologic insulin delivery in patients with type 1 diabetes was compared to a constant infusion of insulin. A euglycemic insulin ( $1 \mathrm{mU} / \mathrm{kg} / \mathrm{min})$ clamp was performed on two occasions. On one occasion, it was infused continuously and, on the other occasion, it was infused for $3 \mathrm{~min}$ followed by a 7 -min rest period. Despite a $40 \%$ reduction in the insulin dose, the suppression of hepatic glucose output was the same. When the total amount of insulin infused was held constant, the hepatic glucose output was 25-30\% less in the cyclical condition [22]. It has also been shown in people with normal glucose metabolism that the dynamic pattern of insulin secretion enhances peripheral glucose uptake more than a continuous infusion [23].

\section{Mechanisms of Insulin Resistance}

Normally, insulin is secreted in a physiologic pattern, mediated by a pancreatic neuronal network connecting cells residing in the islets of Langerhans [24,25]. Dysfunctional 
insulin rhythmicity can occur from a variety of insults (i.e., obesity, auto-immune disorders, toxins, trauma, stress etc.) that lead to inflammation of this network. When physiologic patterns of insulin secretion are disrupted, beta cells secrete insulin asynchronously. As a result of constant ligand/receptor exposure, a negative feedback loop downregulates insulin receptor responsiveness. In addition, lack of physiologic peaks and troughs leads to refractory delays in receptor activity. Finally, disrupted pulsation leads to unopposed glucagon levels, which decrease transcription of insulin receptors [26].

\subsection{Implications for Treatment}

A genetic aspect to insulin resistance (IR) involves abnormal insulin signaling and leads to type 2 diabetes. The children of parents with type 2 diabetes have IR that leads to type 2 diabetes later in their adulthood. These children exhibit higher levels of insulin and beta-cell dysfunction [27]. Even people who are just close relatives of people with type 2 diabetes often have impaired insulin oscillatory patterns [28].

\subsection{Diet}

From a dietary perspective, the Framingham study suggests that diets with a lower glycemic index are associated with greater insulin sensitivity [29]. A low carbohydrate diet is associated with a reduction in IR compared to a high carbohydrate diet [30]. The improvement in insulin oscillation was proportional to residual insulin sensitivity after weight loss [31]. This is, and has been, an approach that targets a reduction in a precursor of the disease manifestations and not just a single symptom. However, it has proved very difficult to obtain patient cooperation in adopting and maintaining an appropriate diet that minimizes carbohydrates and results in achieving and maintaining weight loss $[32,33]$.

\subsection{Medication}

From the medication perspective, as one might predict for a disease driven by IR, insulin sensitizing medication such as metformin or the thiazolidinediones prevent or restore the abnormal insulin secretion associated with IR [34,35]. Repaglinide and glucagon-like peptide-1 agonists increase the insulin peak amplitude without affecting oscillatory frequency [36]. When people with diabetes require insulin, it is given as a subcutaneous injection in a manner that exposes the insulin receptor to a constant level of insulin. Interestingly, some of the common ways of measuring insulin sensitivity are based on fasting insulin and glucose values such as homeostatic model assessment for insulin resistance (HOMA-IR) [37], which may underestimate the role that physiologic insulin cycling plays in IR. All the medications described above deal with controlling the effects of existing diabetes, and not on treating its underlying causes.

As the occurrence of diabetes continues to rise along with the ballooning costs of treatments, pharmaceutical companies continue to seek proprietary compounds for development. In recent years, the US FDA has approved several drugs with novel mechanisms of action. These include GLP-1 agonists, Dipeptidyl peptidase-4 (DPP-4) inhibitors and sodium-glucose transport protein 2 (SGLT2) inhibitors. Thiazolidinediones' such as rosi- and pioglitazone are the only approved insulin sensitizing drugs that use insulin sensitization as the only mechanism. Physiologic insulin resensitization (PIR) is a true sensitizing strategy, as well. Rosiglitizone costs about $\$ 180-\$ 190$ a month but gives an increase of fat cells that fill with fat and increase obesity and therefore include cardiovascular safety concerns.

Although this review was written to focus on approaches that are true insulin sensitizers, such as insulin and the thiazolidinediones, glucagon-like peptide-1 (GLP-1) agonists and sodium-glucose cotransporter-2 (SGLT-2) inhibitors, through their independent mechanisms, have shown a positive effect on insulin resistance. The interested reader can refer to recent reviews on the molecular mechanisms of action of these medications [38,39], since the subject is beyond the scope of the present review. 
It is encouraging to see reductions in major cardiovascular endpoints and positive data for those suffering with renal complications of diabetes. However, the magnitude of such benefits from these novel drugs are limited in scope, while many patients are unable to tolerate due to material adverse side effects [40,41]. In addition, recent guidelines published 5 March 2018, from the American College of Physicians (ACP) on diabetic management outline that over-aggressive $\mathrm{HbA1}$ c control can be counterproductive and harm patients due to complications of hypoglycemia and other untoward effects. This evidence-based review includes data from the landmark ACCORD trial that was terminated prematurely, because intensive glycosylated hemoglobin management led to increased morbidity and mortality. As such, ACP guidelines now target a $\mathrm{HbA} 1 \mathrm{c}$ between $7-8 \%$, rather than previous targets of $6.5-7 \%$. Thus, the standard of practice for diabetic management is in flux, highlighting the need to modify treatment modalities for optimal clinical outcomes [42]. Another important development was the reclassification by the FDA of insulin to the biologic regulatory framework in March of 2020, highlighting the physiologic importance of this hormone peptide in regulating carbohydrate metabolism [43].

\subsection{Physiologic Insulin Resensitization}

An alternative approach to counter IR in the euglycemic clamp of constant insulin infusion would be to reintroduce physiologic insulin delivery. This has been done by inserting an intravenous access connected to a precision infusion pump that can be programmed to dynamically deliver physiologic insulin typical of normal glucose metabolism. A more detailed description of physiologic insulin can be described as periodic cycling of up to 3 IU of regular insulin infused dynamically every 4-8 min (usually 5-6 min), based on the body's utilization for 2 to $4 \mathrm{~h}$ based on an individual patient weekly basis. Oral glucose is given to simulate a meal and to keep blood glucose in a therapeutic and safe range. Patients are observed until glucose is stable after the dynamic insulin infusion is administered [44]. The mechanism of PIR is directed at the pathophysiology of IR, found in type 2 diabetes. Through upregulation of the insulin receptor/ligand complex, it may be possible to bio-modulate physiologic response in a beneficial manner. Peripheral administration of IV insulin in a rhythmic pattern would then be able to replace lost physiological signals critical to cellular glucose metabolism. With improved ability to drive glucose into the mitochondrial oxidative phosphorylation cascade, improved energy production (in the form of ATP) could then occur. As such, energy depleted tissues would have the building blocks necessary to undergo healing, repair, and cellular restoration [45].

Physiologic insulin resensitization requires a pulsatile insulin delivery comparable to that of a healthy pancreas. Understanding this type of insulin delivery is necessary; over the years, scholars have studied and reported on this concept. Notably, in 2012, researchers Matveyenko et al. reported that pulsatile insulin delivery into the systemic circulation is more efficacious than constant insulin infusion [46]. The Matveyenko study also found that the timing of the insulin receptor is perfectly suited to entrain to the episodic delivery of insulin via the sinusoids directly to hepatocytes, and they concluded that hepatic insulin signaling is delayed and impaired when insulin is delivered in a nonpulsatile manner [46].

Ten years earlier, Porksen, et al., discussed pulsatile insulin secretion and reported that, in type 2 diabetes mellitus, both IR and impairment of insulin secretion characterizes the metabolic problem of the disease. High frequency of insulin oscillations in these patients corresponds to serial secretory insulin bursts [47].

This treatment approach has been reported to achieve physiological insulin concentrations in the portal vein based on animal work [48]. This treatment, with some variation on the amount of insulin and treatment frequency, has been evaluated in case series and clinical trials that are reviewed herein. 


\section{Studies of Physiologic Insulin Resensitization (PIR) Treatment}

\subsection{Foot Ulcer and Peripheral Neuropathy}

Tucker et al. described two cases in which symptoms of diabetic neuropathy resolved with PIR. One was a 73-year-old male who displayed slow wound healing, erectile dysfunction, and numbness in his feet with a foot ulcer. Intermittent treatment with PIR achieved wound healing, numbness resolution, and a decrease in his insulin requirement from 120 to 28 units per day. The second was a 74-year-old female who experienced slow wound healing, a foot ulcer, weight gain, stage 4 chronic renal disease, numbness, pain, and tingling in her lower extremities. Over several months of receiving insulin administered in a physiologic manner, she experienced wound healing, improved sensation, and discontinuance of the gabapentin formerly taken for neuropathy pain. She also lost $15 \mathrm{~kg}$, her daily insulin requirement dropped from 60 to 25 units per day, and her $\mathrm{HbA1c}$ dropped from 9.9 to $7.1 \%$ [49]. In another study Elliott et al. described a case series of 5 patients who were treated with physiologic insulin $1 \mathrm{~h} 3$ times a day up to 5 days a week. The mean time to complete healing of foot ulcers was predicted from the literature to be 133 days, but the wounds in the 5 patients healed in a mean of 84 days [50]. The 37\% reduction in the healing time was interpreted as providing a significant cost savings [51]. Dailey et al. randomly allocated 19 patients (12 men, 7 women) to either standard diabetic insulin-based care or to that care and additional day per week of 3 sessions of physiologic insulin over an 8 -h period. When compared to baseline perceptions, patients receiving physiologic insulin reported significant improvement in diabetic nephropathy when compared to the control group ( $p=0.0144$ ) [52]. Eliott et al. reported on a study of 412 patients, $76 \%$ of whom experienced painful diabetic neuropathy and who were treated with $3 \mathrm{~h}$ of physiologic insulin per week for 3 months. Of those with painful diabetic neuropathy, 142 (47.5\% experienced complete resolution of pain, 136 (45.5\%) experienced partial resolution of pain and $21(7 \%)$ experienced no improvement [51].

\subsection{Diabetic Nephropathy}

Villaverde et al. described three cases of chronic kidney disease, one in a patient with diabetes and two with pre-diabetes, that improved in response to physiologic insulin resensitization over 5-6 months. The estimated glomerular filtration rate (GFR) increased from 33, 34 and $54 \mathrm{cc} / \mathrm{min}$ to 55,42 and $74 \mathrm{cc} /$ minute, respectively. Blood urea nitrogen and creatinine improved from means of 27 and $1.7 \mathrm{mg} / \mathrm{dL}$ to 13 and $1.2 \mathrm{mg} / \mathrm{dL}$, respectively. Not only is reversal of chronic kidney disease difficult to accomplish, but delaying renal replacement therapy is also associated with significant economic savings [53]. Manessis et al. reported an uncontrolled series of 17 patients with type 2 diabetes of greater than 2 years duration and stage 3 chronic kidney disease (GFR 30-60 cc/min) treated with weekly dynamic physiologic insulin for 3 months. The GFR increased by $12 \%$ from baseline $(47.6 \pm 10 \mathrm{cc} / \mathrm{min}$ to $53.3 \pm 11.9, p<0.01)$, creatinine decreased by $7 \%$ from baseline $(p<0.05)$, and systolic blood pressure decreased by $6 \%$ from baseline $(p<0.05)$ [54]. Quach and Manessis conducted a trial of 17 patients with chronic kidney failure. Patients received a total of 10 physiologic insulin infusion procedures over three months. GFR improved by an average of $10.8 \%$ and creatinine decreased by $6.8 \%$ [55]. Dailey et al. compared two randomly assigned groups of 49 patients who received either intensive diabetes treatment only (26) or intensive treatment plus physiologic insulin infusions (23). Creatinine clearance $(\mathrm{CrCl})$ declined significantly in both groups, as expected, but the rate of $\mathrm{CrCl}$ decline in the group receiving physiologic insulin $(2.21 \pm 1.62 \mathrm{~mL} / \mathrm{min} / \mathrm{yr})$ was significantly less than in the control group $(7.69 \pm 1.88 \mathrm{~mL} / \mathrm{min} / \mathrm{yr}, p=0.0343)$ [52]. An overall summary of the physiologic insulin resensitization effect on diabetic nephropathy is provided in Table 1.

\section{3. $\mathrm{HbA1c}$}

Tucker et al. reported a 74-year-old female who presented with numerous complications after 20 years of T2D that included slow wound healing, foot ulcers, kidney disease, neuropathy, and hypertension. Her comparisons before and after PIR treatment 
included $\mathrm{HbA1c}$ reduction from 9.9 to 7.1, improved wound healing and discontinuance of Gabapentin for neuropathy, and discontinuance of her Humalog completely [49].

Table 1. Summary of benefits from physiologic insulin resensitization in treating diabetic nephropathy.

Improvements in the Progression of Diabetic Nephropathy

\begin{tabular}{ll}
\hline Halting the Progression of CKD: CrCl (18 months) [52] & $348 \%$ \\
\hline Reversals of CKD: Improved EGFR (3.75 months) [53] & $44 \%$ \\
\hline Reversals of CKD: Improved EGFR (3 months) [54] & $12 \%$ \\
\hline
\end{tabular}

Aoki et al. treated 20 patients with brittle type 1 diabetes for periods of 7-71 months with physiologic insulin and the mean $\mathrm{HbA1c}$ declined from $8.5 \%$ to $7.0 \%$ [56]. Aoki reported on another study of 31 patients with type 1 diabetes, many with diabetes complications, who were controlled on a physiologic insulin regimen with injections administered 4 times a day. These patients were treated with additional oscillatory intravenous insulin for $1 \mathrm{~h}$ during meals 3 times a day, 1 day a week, for 7 to 71 months. The HbA1c fell from $8.5 \%$ to $7.0 \%$. Major hypoglycemic reactions fell from 3 to 0.1 per month, and minor hypoglycemic reactions fell from 13 to 2.4 per month [44].

\subsection{Cost Reduction}

All the studies above reflected reduced burden of disease. However, they did not study the actual or potential saving that may have accrued because of the intervention. Another study gave data for the likely savings that are possible. Elliott et al. reported an observational study that included 1524 patients with diabetes who had two or more complications and who were treated with 3-h (weekly or at longer intervals) physiologic insulin for 2 years [51]. The number of expected hospital admissions was 47 out of 100 patients per year, but only 5 were observed and the number of expected and observed emergency room visits per year was 58 and 7 , respectively $(p<0.0001)$ [51].

\section{Conclusions}

Based on the evidence, loss of dynamic physiologic insulin signaling plays a major role in the pathophysiology of insulin resistance (IR). Given that IR is the accepted basis for type 2 diabetes. It, therefore, seems logical that the treatment of type 2 diabetes would be improved by switching from standard insulin treatment to a treatment that bio-mimics the normal physiologic insulin signaling process. Skjaervold et al. have been exploring the pharmacology of intravenous physiologic insulin administration as a prelude to a closed-loop intravenous insulin pump to replace the insulin pumps presently available that use a constant infusion of insulin administered by a subcutaneous route [57]. One can imagine that the next step in such a progression will be the inclusion of glucagon pulses in between the insulin pulses to further mimic the physiology of human insulin and glucagon secretion.

We firmly believe that the evidence supports the assertion that physiologic insulin secretion is crucial in the maintenance of normal cellular insulin sensitivity. Hence, using physiologic insulin resensitization is a logical approach to restoring normal insulin function. The case studies and clinical trials examining efficacy presented in this paper are insufficient to prove the hypothesis that biomimicry of the physiologic insulin administration in this manner is broadly efficacious. Randomized clinical trial are needed. However, these reports and studies have consistently shown improvement in the usually refractory conditions that are associated with diabetes. Moreover, they demonstrate that physiologic insulin resensitization can affect several of the untoward manifestations of diabetes and, thus, appears to address the root causes of IR. They also suggest that the complications, hospitalizations, medication costs, and emergency room visits may be reduced using physiologic insulin resensitization (Tables 2 and 3). 
Table 2. Clinical Outcomes Utilizing Physiologic Insulin Resensitization.

\begin{tabular}{l}
\hline Decreases in Hemoglobin A1c [49,58] \\
\hline Reversals of Diabetic Neuropathy [49] \\
\hline Improvements in Wound Healing [49] \\
\hline Decreases in Insulin Requirements [49] \\
\hline Improvements in Estimated Glomerular Filtration Rate (eGFR) [53,54] \\
\hline Decreases in Systolic Blood Pressure (SBP) [54] \\
\hline Reduce/Arrest Progression of Diabetic Nephropathy [49,52,54,58] \\
\hline
\end{tabular}

Table 3. Summary of study results discussed in this article.

\begin{tabular}{llll}
\hline \multicolumn{1}{c}{ Reference } & \multicolumn{1}{c}{ Finding } & \multicolumn{1}{c}{ Study Design } & \multicolumn{1}{c}{ Results } \\
Tucker et al. & Neuropathy & Case Series & $\begin{array}{l}\text { Improved; discontinued } \\
\text { Gabapentin }\end{array}$ \\
\hline Tucker et al. & Foot Ulcer & Case Series & Healed quickly \\
\hline Tucker et al. & HbA1c & Case Report & HbA1c decreased 2.8 \\
\hline Elliott et al. & Foot Ulcer & Case Series & Healed 1/3 more quickly \\
\hline Dailey et al. & Nephropathy & Controlled Trial & Improved ( $p=0.0144)$ \\
\hline Elliott et al. & Neuropathy Pain & Case Series & 93\% improved, 47.5\% resolved \\
\hline Villaverde et al. & Nephropathy & Case Series & $41 \%$ increase in GFR \\
\hline Manessis et al. & Nephropathy & Case Series & $12 \%$ increase in GFR \\
\hline Quach et al. & Nephropathy & Case Series & $11 \%$ increase in GFR \\
\hline Dailey et al. & Nephropathy & Controlled Trial & Reduced decline in GFR \\
\hline Aoki et al. & HbA1c & Case Series & HbA1c decreased by 1.5 T1D \\
\hline Aoki et al. & HbA1c & Case Series & $\begin{array}{l}\text { HbA1c decreased by } 1 ; \\
\text { improved glycemic control }\end{array}$ \\
\hline Elliott et al. & Hospitalizations & Case Series & Reduced hospitalizations \\
\hline
\end{tabular}

This needs further research that examines the treatment's effect on a broad array of diabetes complications. These studies should also include examining the cost of the treatment versus the costs avoided by it. If randomized controlled studies replicate the outcomes of case reports and studies examined in this review, administration of insulin in a physiologic manner represents a promising approach to reduce or avoid the looming increases in disease, disability, death and cost that will occur as the 88 million pre-diabetics progress to overt diabetes in the United States.

Author Contributions: Conceptualization, F.G., B.L., J.R.T.L., S.A.H.; writing-original draft preparation, F.G., R.M.G., C.N.-J.; writing-review and editing, B.L., J.R.T.L., S.A.H., T.R.T., S.T.L., M.A. (Michael Alexander), M.A. (Mohammed Abdelsaid), C.W., A.M.S., J.F.; funding acquisition, F.G. All authors have read and agreed to the published version of the manuscript.

Funding: This manuscript was supported in part by 1 U54 GM104940 from the National Institute of General Medical Sciences of the National Institutes of Health which funds the Louisiana Clinical and Translational Science Center. The content is solely the responsibility of the authors and does not necessarily represent the official views of the National Institutes of Health.

Institutional Review Board Statement: Not applicable.

Informed Consent Statement: Not applicable.

Data Availability Statement: Not applicable. 
Conflicts of Interest: The authors declare no conflict of interest. The funders had no role in the design of the study; in the collection, analyses, or interpretation of data; in the writing of the manuscript, or in the decision to publish the results.

\section{References}

1. Center for Disease Control and Prevention. Long-Term Trends in Diabetes. Available online: https://www.cdc.gov/diabetes / statistics/slides/long_term_trends.pdf (accessed on 21 December 2021).

2. Center for Disease Control and Prevention. 2020 National Diabetes Statistics Report; US Department of Health and Human Services: Atlanta, GA, USA, 2020.

3. Tabak, A.G.; Herder, C.; Rathmann, W.; Brunner, E.J.; Kivimaki, M. Prediabetes: A high-risk state for diabetes development. Lancet 2012, 379, 2279-2290. [CrossRef]

4. American Diabetes Association. Economic costs of diabetes in the U.S. 2017. Diabetes Care 2018, 41, 917-928. [CrossRef] [PubMed]

5. American Diabetes Association. 9. Pharmacologic approaches to glycemic treatment: Standards of medical care in diabetes-2021. Diabetes care 2021, 44, S111-S124. [CrossRef] [PubMed]

6. Colling, C.; Atlas, S.J.; Wexler, D.J. Application of 2021 american diabetes association glycemic treatment clinical practice recommendations in primary care. Diabetes Care 2021, 44, 1443-1446. [CrossRef] [PubMed]

7. American Diabetes Association. Introduction: Standards of medical care in diabetes-2021. Diabetes Care 2021, 44, S1-S2. [CrossRef] [PubMed]

8. Food and Drug Administration. Fda Revises Labels of Sglt2 Inhibitors for Diabetes to Include Warnings about Too Much Acid in the Blood and Serious Urinary Tract Infections. Available online: https://www.fda.gov/drugs/drug-safety-andavailability / fda-revises-labels-sglt2-inhibitors-diabetes-include-warnings-about-too-much-acid-blood-and-serious (accessed on 19 January 2010).

9. Adhikari, R.; Blaha, M. New Insights into Prescribing of Sglt2 Inhibitors and Glp-1 Receptor Agonists by Cardiologists in 2020: Major Barriers Limiting Role. Available online: https:/ /www.acc.org/latest-in-cardiology/articles/2021/01/19/14/27/newinsights-into-prescribing-of-sglt2-inhibitors-and-glp-1-receptor-agonists-in-2020 (accessed on 19 January 2021).

10. Kahn, S.E.; Montgomery, B.; Howell, W.; Ligueros-Saylan, M.; Hsu, C.H.; Devineni, D.; McLeod, J.F.; Horowitz, A.; Foley, J.E. Importance of early phase insulin secretion to intravenous glucose tolerance in subjects with type 2 diabetes mellitus. J. Clin. Endocrinol. Metab. 2001, 86, 5824-5829. [CrossRef] [PubMed]

11. Del Prato, S.; Tiengo, A. The importance of first-phase insulin secretion: Implications for the therapy of type 2 diabetes mellitus. Diabetes Metab. Res. Rev. 2001, 17, 164-174. [CrossRef] [PubMed]

12. Abbvie. Lupron Depot-Ped: Dosing and Administration. Available online: https://www.lupronpedpro.com/dosing-andadministration.html (accessed on 31 August 2021).

13. Lang, D.A.; Matthews, D.R.; Peto, J.; Turner, R.C. Cyclic oscillations of basal plasma glucose and insulin concentrations in human beings. N. Engl. J. Med. 1979, 301, 1023-1027. [CrossRef] [PubMed]

14. Kanauchi, M.; Nakajima, M.; Saito, Y.; Kanauchi, K. Pancreatic beta-cell function and insulin sensitivity in japanese subjects with impaired glucose tolerance and newly diagnosed type 2 diabetes mellitus. Metabolism 2003, 52, 476-481. [CrossRef] [PubMed]

15. Ahren, B. Autonomic regulation of islet hormone secretion-implications for health and disease. Diabetologia 2000, 43, 393-410. [CrossRef] [PubMed]

16. Hellman, B.; Salehi, A.; Gylfe, E.; Dansk, H.; Grapengiesser, E. Glucose generates coincident insulin and somatostatin pulses and antisynchronous glucagon pulses from human pancreatic islets. Endocrinology 2009, 150, 5334-5340. [CrossRef]

17. Song, S.H.; McIntyre, S.S.; Shah, H.; Veldhuis, J.D.; Hayes, P.C.; Butler, P.C. Direct measurement of pulsatile insulin secretion from the portal vein in human subjects. J. Clin. Endocrinol. Metab. 2000, 85, 4491-4499. [CrossRef]

18. Laurenti, M.C.; Matveyenko, A.; Vella, A. Measurement of pulsatile insulin secretion: Rationale and methodology. Metabolites 2021, 11, 409. [CrossRef]

19. Butler, A.E.; Janson, J.; Bonner-Weir, S.; Ritzel, R.; Rizza, R.A.; Butler, P.C. Beta-cell deficit and increased beta-cell apoptosis in humans with type 2 diabetes. Diabetes 2003, 52, 102-110. [CrossRef]

20. Ferrannini, E.; Gastaldelli, A.; Miyazaki, Y.; Matsuda, M.; Mari, A.; DeFronzo, R.A. Beta-cell function in subjects spanning the range from normal glucose tolerance to overt diabetes: A new analysis. J. Clin. Endocrinol. Metab. 2005, 90, 493-500. [CrossRef]

21. McGuinness, O.P.; Friedman, A.; Cherrington, A.D. Intraportal hyperinsulinemia decreases insulin-stimulated glucose uptake in the dog. Metabolism 1990, 39, 127-132. [CrossRef]

22. Bratusch-Marrain, P.R.; Komjati, M.; Waldhausl, W.K. Efficacy of pulsatile versus continuous insulin administration on hepatic glucose production and glucose utilization in type i diabetic humans. Diabetes 1986, 35, 922-926. [CrossRef] [PubMed]

23. Schmitz, O.; Arnfred, J.; Nielsen, O.H.; Beck-Nielsen, H.; Orskov, H. Glucose uptake and pulsatile insulin infusion: Euglycaemic clamp and $\left[3^{3} \mathrm{H}\right]$ glucose studies in healthy subjects. Acta Endocrinol. (Copenh.) 1986, 113, 559-563. [CrossRef] [PubMed]

24. Stanley, S.; Moheet, A.; Seaquist, E.R. Central mechanisms of glucose sensing and counterregulation in defense of hypoglycemia. Endocr. Rev. 2019, 40, 768-788. [CrossRef]

25. Rosario, W.; Singh, I.; Wautlet, A.; Patterson, C.; Flak, J.; Becker, T.C.; Ali, A.; Tamarina, N.; Philipson, L.H.; Enquist, L.W.; et al. The brain-to-pancreatic islet neuronal map reveals differential glucose regulation from distinct hypothalamic regions. Diabetes 2016, 65, 2711-2723. [CrossRef] 
26. Satin, L.S.; Butler, P.C.; Ha, J.; Sherman, A.S. Pulsatile insulin secretion, impaired glucose tolerance and type 2 diabetes. Mol. Asp. Med. 2015, 42, 61-77. [CrossRef] [PubMed]

27. Stadler, M.; Pacini, G.; Petrie, J.; Luger, A.; Anderwald, C.; Investigators, R. Beta cell (dys)function in non-diabetic offspring of diabetic patients. Diabetologia 2009, 52, 2435-2444. [CrossRef]

28. O'Rahilly, S.; Turner, R.C.; Matthews, D.R. Impaired pulsatile secretion of insulin in relatives of patients with non-insulindependent diabetes. N. Engl. J. Med. 1988, 318, 1225-1230. [CrossRef] [PubMed]

29. McKeown, N.M.; Meigs, J.B.; Liu, S.; Saltzman, E.; Wilson, P.W.; Jacques, P.F. Carbohydrate nutrition, insulin resistance, and the prevalence of the metabolic syndrome in the framingham offspring cohort. Diabetes Care 2004, 27, 538-546. [CrossRef]

30. McAuley, K.A.; Hopkins, C.M.; Smith, K.J.; McLay, R.T.; Williams, S.M.; Taylor, R.W.; Mann, J.I. Comparison of high-fat and high-protein diets with a high-carbohydrate diet in insulin-resistant obese women. Diabetologia 2005, 48, 8-16. [CrossRef]

31. Ajala, O.; English, P.; Pinkney, J. Systematic review and meta-analysis of different dietary approaches to the management of type 2 diabetes. Am. J. Clin. Nutr. 2013, 97, 505-516. [CrossRef]

32. Feldstein, A.C.; Nichols, G.A.; Smith, D.H.; Stevens, V.J.; Bachman, K.; Rosales, A.G.; Perrin, N. Weight change in diabetes and glycemic and blood pressure control. Diabetes Care 2008, 31, 1960-1965. [CrossRef]

33. Zarkovic, M.; Ciric, J.; Penezic, Z.; Trbojevic, B.; Drezgic, M. Effect of weight loss on the pulsatile insulin secretion. J. Clin. Endocrinol. Metab. 2000, 85, 3673-3677. [CrossRef]

34. Lupi, R.; Del Guerra, S.; Marselli, L.; Bugliani, M.; Boggi, U.; Mosca, F.; Marchetti, P.; Del Prato, S. Rosiglitazone prevents the impairment of human islet function induced by fatty acids: Evidence for a role of ppargamma2 in the modulation of insulin secretion. Am. J. Physiol. Endocrinol. Metab. 2004, 286, E560-E567. [CrossRef] [PubMed]

35. Patane, G.; Piro, S.; Rabuazzo, A.M.; Anello, M.; Vigneri, R.; Purrello, F. Metformin restores insulin secretion altered by chronic exposure to free fatty acids or high glucose: A direct metformin effect on pancreatic beta-cells. Diabetes 2000, 49, 735-740. [CrossRef]

36. Ritzel, R.; Schulte, M.; Porksen, N.; Nauck, M.S.; Holst, J.J.; Juhl, C.; Marz, W.; Schmitz, O.; Schmiegel, W.H.; Nauck, M.A Glucagon-like peptide 1 increases secretory burst mass of pulsatile insulin secretion in patients with type 2 diabetes and impaired glucose tolerance. Diabetes 2001, 50, 776-784. [CrossRef] [PubMed]

37. Wallace, T.M.; Levy, J.C.; Matthews, D.R. Use and abuse of homa modeling. Diabetes Care 2004, 27, 1487-1495. [CrossRef] [PubMed]

38. Papazafiropoulou, A.K.; Melidonis, A.; Antonopoulos, S. Effects of glucagon-like peptide-1 receptor agonists and sodium-glucose cotransporter 2 inhibitors on cardiorenal and metabolic outcomes in people without diabetes. Curr. Pharm. Des. 2021, 27, 1035-1042. [CrossRef] [PubMed]

39. Yaribeygi, H.; Sathyapalan, T.; Maleki, M.; Jamialahmadi, T.; Sahebkar, A. Molecular mechanisms by which sglt2 inhibitors can induce insulin sensitivity in diabetic milieu: A mechanistic review. Life Sci. 2020, 240, 117090. [CrossRef] [PubMed]

40. Gerstein, H.C.; Colhoun, H.M.; Dagenais, G.R.; Diaz, R.; Lakshmanan, M.; Pais, P.; Probstfield, J.; Riesmeyer, J.S.; Riddle, M.C.; Ryden, L.; et al. Dulaglutide and cardiovascular outcomes in type 2 diabetes (rewind): A double-blind, randomised placebocontrolled trial. Lancet 2019, 394, 121-130. [CrossRef]

41. Wiviott, S.D.; Raz, I.; Bonaca, M.P.; Mosenzon, O.; Kato, E.T.; Cahn, A.; Silverman, M.G.; Zelniker, T.A.; Kuder, J.F.; Murphy, S.A.; et al. Dapagliflozin and cardiovascular outcomes in type 2 diabetes. N. Engl. J. Med. 2019, 380, 347-357. [CrossRef]

42. Qaseem, A.; Wilt, T.J.; Kansagara, D.; Horwitch, C.; Barry, M.J.; Forciea, M.A.; Clinical Guidelines Committee of the American College of Physicians. Hemoglobin a1c targets for glycemic control with pharmacologic therapy for nonpregnant adults with type 2 diabetes mellitus: A guidance statement update from the american college of physicians. Ann. Intern. Med. 2018, 168, 569-576. [CrossRef]

43. Abernethy, A. Insulin Gains New Pathway to Increased Competition. Available online: https://www.fda.gov/news-events/ press-announcements/insulin-gains-new-pathway-increased-competition (accessed on 28 April 2021).

44. Aoki, T.T.; Grecu, E.O.; Arcangeli, M.A.; Benbarka, M.M.; Prescott, P.; Ahn, J.H. Chronic intermittent intravenous insulin therapy: A new frontier in diabetes therapy. Diabetes Technol. Ther. 2001, 3, 111-123. [CrossRef]

45. Dong, S.; Lau, H.; Chavarria, C.; Alexander, M.; Cimler, A.; Elliott, J.P.; Escovar, S.; Lewin, J.; Novak, J.; Lakey, J.R.T. Effects of periodic intensive insulin therapy: An updated review. Curr. Ther. Res. Clin. Exp. 2019, 90, 61-67. [CrossRef]

46. Matveyenko, A.V.; Liuwantara, D.; Gurlo, T.; Kirakossian, D.; Dalla Man, C.; Cobelli, C.; White, M.F.; Copps, K.D.; Volpi, E.; Fujita, S.; et al. Pulsatile portal vein insulin delivery enhances hepatic insulin action and signaling. Diabetes 2012, 61, 2269-2279. [CrossRef]

47. Porksen, N.; Hollingdal, M.; Juhl, C.; Butler, P.; Veldhuis, J.D.; Schmitz, O. Pulsatile insulin secretion: Detection, regulation, and role in diabetes. Diabetes 2002, 51 (Suppl. 1), S245-S254. [CrossRef]

48. Farmer, T.D.; Jenkins, E.C.; O’Brien, T.P.; McCoy, G.A.; Havlik, A.E.; Nass, E.R.; Nicholson, W.E.; Printz, R.L.; Shiota, M. Comparison of the physiological relevance of systemic vs. Portal insulin delivery to evaluate whole body glucose flux during an insulin clamp. Am. J. Physiol. Endocrinol. Metab. 2015, 308, E206-E222. [CrossRef]

49. Tucker, T.; Hadley, J.; Alexander, M.; Lakey, J.; Loveridge, B. Case series: Reversal of diabetic neuropathy utilizing physiologic insulin resensitization. Int. J. Diab. Metab. Disord. 2021, 6, 163.

50. Elliott, J.; Elliott, A.; Cimler, A.; Zaias, N.; Escovar, S. Extraordinary rapid would healing time in diabetic patients treated with microburst insulin infusion. Int. Res. J. Publ. Health 2018, 2, 9. 
51. Elliott, J.; Zaias, N.; Escovar, S.; Deguzman, L.; Counce, D.; Dixit, R.; Capper, D.; Novak, J.; Nowins, R.; Holloway, W.; et al. Microburst insulin infusion: Results of observational studies-Carbohydrate metabolism, painful diabetic neuropathy and hospital/emergency department utilization. J. Diab. Metab. Disord. Contr. 2017, 4, 116-121.

52. Dailey, G.E.; Boden, G.H.; Creech, R.H.; Johnson, D.G.; Gleason, R.E.; Kennedy, F.P.; Weinrauch, L.A.; Weir, M.; D’Elia, J.A. Effects of pulsatile intravenous insulin therapy on the progression of diabetic nephropathy. Metabolism 2000, 49, 1491-1495. [CrossRef] [PubMed]

53. Villaverde, Z.; Tucker, T.; Hepford, S.; Lakey, J.; Hinman, R. Improved kidney function following physiologic insulin resensitization treatment modality. J. Endocrinol. Disord. 2021, 5. [CrossRef]

54. Manessis, A.; Hanna, M.; Sachsenheimer, D.; Do, L.; Lewin, J.; Steiner, S.; McCormack, S.; Demircik, F.; Pfutzner, A. Pulsatile insulin infusion as a treatment option for patients with type 2 diabetes and stage iii kidney failure-Results from a pilot study. Diabetes care 2021, 6, 49-54.

55. Quach, S.; Manessis, A. 112-lb: Pulsatile insulin treatment as a treatment option for patients with type 2 diabetes and stage 3 kidney failure. Diabetes 2021, 70, 70. [CrossRef]

56. Aoki, T.T.; Benbarka, M.M.; Okimura, M.C.; Arcangeli, M.A.; Walter, R.M., Jr.; Wilson, L.D.; Truong, M.P.; Barber, A.R.; Kumagai, L.F. Long-term intermittent intravenous insulin therapy and type 1 diabetes mellitus. Lancet 1993, 342, 515-518. [CrossRef]

57. Skjaervold, N.K.; Lyng, O.; Spigset, O.; Aadahl, P. Pharmacology of intravenous insulin administration: Implications for future closed-loop glycemic control by the intravenous/intravenous route. Diabetes Technol. Ther. 2012, 14, 23-29. [CrossRef] [PubMed]

58. Aoki, T.T.; Grecu, E.O.; Gollapudi, G.M.; Barber, A.R.; Arcangeli, M.A.; Benbarka, M.M.; Prescott, P.; Meisenheimer, R. Effect of intensive insulin therapy on progression of overt nephropathy in patients with type 1 diabetes mellitus. Endocr. Pract. 1999, 5, 174-178. [CrossRef] [PubMed] 